\title{
Computational Identification of Novel Kir6 Channel Inhibitors
}

\author{
Xingyu Chen 1 , Arthur Garon², Marcus Wieder², Marien J. C. Houtman ${ }^{3}$, \\ Eva-Maria Zangerl-Pless/1, Thierry Langer ${ }^{2}$, Marcel A. G. van der Heyden ${ }^{1,3}$ and \\ Anna Stary-Weinzinger ${ }^{1 *}$ \\ ${ }^{1}$ Department of Pharmacology and Toxicology, University of Vienna, Vienna, Austria, ${ }^{2}$ Department of Pharmaceutical \\ Chemistry, University of Vienna, Vienna, Austria, ${ }^{3}$ Department of Medical Physiology, Division of Heart and Lungs, University \\ Medical Center Utrecht, Utrecht, Netherlands
}

\section{OPEN ACCESS}

Edited by:

Gildas Loussouarn University of Nantes, France

Reviewed by:

Roope Mannikko, University College London,

United Kingdom

Hiroshi Hibino,

Niigata University, Japan

Michel Vivaudou,

UMR5075 Institut de Biologie

Structurale (IBS), France

${ }^{*}$ Correspondence:

Anna Stary-Weinzinger

anna.stary@univie.ac.at

Specialty section:

This article was submitted to Pharmacology of Ion Channels and Channelopathies, a section of the journal

Frontiers in Pharmacology

Received: 04 February 2019 Accepted: 01 May 2019

Published: 24 May 2019

Citation:

Chen X, Garon A, Wieder M, Houtman MJC, Zangerl-Pless/ E-M, Langer T, van der Heyden MAG and Stary-Weinzinger A (2019) Computational Identification of Novel Kir6 Channel Inhibitors. Front. Pharmacol. 10:549. doi: 10.3389/fphar.2019.00549
KATP channels consist of four Kir6.x pore-forming subunits and four regulatory sulfonylurea receptor (SUR) subunits. These channels couple the metabolic state of the cell to membrane excitability and play a key role in physiological processes such as insulin secretion in the pancreas, protection of cardiac muscle during ischemia and hypoxic vasodilation of arterial smooth muscle cells. Abnormal channel function resulting from inherited gain or loss-of-function mutations in either the Kir6.x and/or SUR subunits are associated with severe diseases such as neonatal diabetes, congenital hyperinsulinism, or Cantú syndrome (CS). CS is an ultra-rare genetic autosomal dominant disorder, caused by dominant gain-of-function mutations in SUR2A or Kir6.1 subunits. No specific pharmacotherapeutic treatment options are currently available for CS. Kir6 specific inhibitors could be beneficial for the development of novel drug therapies for CS, particular for mutations, which lack high affinity for sulfonylurea inhibitor glibenclamide. By applying a combination of computational methods including atomistic MD simulations, free energy calculations and pharmacophore modeling, we identified several novel Kir6.1 inhibitors, which might be possible candidates for drug repurposing. The in silico predictions were confirmed using inside/out patch-clamp analysis. Importantly, Cantú mutation C166S in Kir6.2 (equivalent to C176S in Kir6.1) and S1020P in SUR2A, retained high affinity toward the novel inhibitors. Summarizing, the inhibitors identified in this study might provide a starting point toward developing novel therapies for Cantú disease.

Keywords: KATP channel, Cantú syndrome, molecular dynamics simulation, dynamic pharmacophore, channelopathy, electrophysiology

\section{INTRODUCTION}

Cantú syndrome (CS) is a rare genetic autosomal dominant disorder caused by dominant gain-of-function mutations in the ATP-dependent potassium (KATP) channel genes ABCC9 (Harakalova et al., 2012; Van Bon et al., 2012) and KCNJ8 (Brownstein et al., 2013; Cooper et al., 2014, 2017), encoding sulfonylurea receptor 2 SUR2 and inward rectifier potassium channel 6.1 Kir6.1, respectively. Cantú patients are chronically ill; they suffer from congenital hypertrichosis, distinctive facial features and cardiac defects (Cantú et al., 1982; Scurr et al., 2011; Nichols et al., 2013) and have a decreased life expectancy. Currently, no specific pharmacotherapeutic options are available to treat the disease (Kharade et al., 2016). 
Recent breakthroughs in solving atomic and near-atomic resolution structures of eukaryotic inward rectifier potassium (Kir) channels provide an excellent opportunity to investigate the structural basis of CS mutations and for developing novel therapies for KATP channelopathies. Starting from January 2017, the first (near-)atomic resolution structures (resolution ranges from 3.63 to $6.3 \AA$ ) of these hetero-octameric complexes have been solved by cryo-EM microscopy by three independent labs (Lee et al., 2017; Li et al., 2017; Martin et al., 2017a,b; Wu et al., 2018). These structures confirm that KATP channels are formed by four Kir6.x pore-forming subunits and four regulatory sulfonylurea receptor (SUR) subunits.

KATP channels couple the metabolic state of the cell to membrane excitability and play a key role in physiological processes such as insulin secretion in the pancreas (Ashcroft, 2005), protection of cardiac muscle during ischemia (Nichols and Lederer, 1991; Crawford et al., 2002; Zingman et al., 2007), and hypoxic vasodilation of arterial smooth muscle cells (Dart and Standen, 1995).

Channel activity is regulated by voltage and ligands. While inhibitory adenosine-triphosphate (ATP) binds to the Kir6.x subunit, magnesium-adenosine-triphosphate-(MgATP), and adenosine-diphosphate (ADP) activate the channel via interacting with the SUR subunits (Matsuo et al., 1999, 2000; Tanabe et al., 1999; Ueda et al., 1999; MacGregor et al., 2002; Vanoye et al., 2002). Phospholipid phosphatidylinositol4,5-bisphosphate $\left(\mathrm{PIP}_{2}\right)$, is necessary for channel opening of all inward rectifying potassium channels and binds to the Kir6.x subunit (Huang et al., 1998; Shyng and Nichols, 1998; Zhang et al., 1999). Abnormal channel function, resulting from inherited gain or loss-of-function mutations in either the Kir6.x and/or SUR subunits are associated with severe diseases such as neonatal diabetes, congenital hyperinsulinism and CS (Remedi and Nichols, 2009; Harakalova et al., 2012). Further, SUR2 subunits have been shown to play a role in human neurological disease, including prevalent diseases of the aged brain (Nelson et al., 2015).

Pharmaceutical interventions in KATP channels include sulfonylurea-like inhibitors such as glibenclamide and channel openers, such as diazoxide, which are clinically used to treat neonatal diabetes and hypertension and target the sulfonylurea subunits (Gribble and Reimann, 2003; Pearson et al., 2006). More recently, side effects due to inhibition of KATP channels have been reported as well. For example, in Yu et al. (2011) reported that all isoforms of KATP channels are blocked by rosiglitazone (RSG) at micro molar concentrations, which could be harmful due to promotion of adverse cardiovascular effects. RSG is a high-affinity agonist of the peroxisome proliferator-activated receptor $\gamma$, which was introduced in 1999 for the treatment of type II diabetes mellitus. The drug increases insulin sensitivity in fat cells by regulating genes involved in glucose and lipid metabolism and might have additional beneficial effects including anti-atherosclerotic, anti-inflammatory, and anticancer effects (Brown and Plutzky, 2007). Due to reports of increased risk of myocardial infarction, RSG was withdrawn from the market in Europe in 2010 (Agency European Medicines, 2010) and had its access restricted in the United States by the FDA in
2011 (U.S. Food and Drug Administration, 2011). Recently it was shown that this increased cardiovascular risk might be due to modification of different ion channels including Kv4.3, L-type calcium channels and KATP channels (Hancox, 2011; Jeong et al., 2011; Szentandrássy et al., 2011; Yu et al., 2011, 2012). Studies on pigs demonstrate that RSG and other thiazolidinedione drugs can block cardiac sarcolemmal KATP channels in vivo at clinically relevant doses (Lu et al., 2008). The reported $\mathrm{IC}_{50}$ of this drug is $45 \mu \mathrm{M}$ for Kir6.2/SURx (pancreatic and heart) channels and $10 \mu \mathrm{M}$ for vascular Kir6.1/SUR2B. Interestingly, potency has been shown to be even higher in the presence of therapeutic concentrations of sulfonylureas reducing the $\mathrm{IC}_{50}$ to $2 \mu \mathrm{M}$. Since plasma concentrations of RSG used to treat type II diabetes mellitus are in the range of $3 \mu \mathrm{M}$ (Cox et al., 2000), block of KATP channels could be a serious problem. Experiments performed on Kir6.2 $\Delta$ C36 constructs revealed that the drug acts predominantly on the pore-forming Kir6.x subunits and not on the SUR subunits. Further analysis of single KATP channels suggests that the drug suppresses channel activity by extending long-lasting channel closures, most likely via modulating the gating mechanism (Yu et al., 2012).

Kir6 inhibitors such as RSG, which block channels at clinically relevant doses, could provide a good starting point toward development of novel, specific inhibitors, suitable for developing drugs toward treatment of CS. Thus, in this study, we applied a novel combination of computational methods to investigate the structural mechanism of block of RSG in Kir6 channels. We carried out extensive unbiased full atomistic simulations of drug binding to the closed channel state. Based on the thereby identified binding site, we postulate a structural mechanism by which the drug might prolong the long-closed state of the channel. Further, structure-based pharmacophore models were constructed to enable identification of novel Kir6 inhibitors, which might be useful for future drug development to treat Cantú disease.

\section{RESULTS AND DISCUSSION}

Based on the experimental finding that RSG predominantly acts on the long-closed state of Kir6.1 channels (Yu et al., 2012), a homology model of the Kir6.1 pore model was constructed using the closed state crystal structure of the Kir3.2 channel [Protein Data Bank (PDB) code: 3SYA (Whorton and MacKinnon, 2011)] as template. A sequence alignment is shown in Supplementary Figure S1A. The root mean square deviation (RMSD) of the Kir6.1 model converged to $\sim 4 \AA$ at around $100 \mathrm{ns,} \mathrm{indicating}$ that the simulated systems are stable and at equilibrium (see Supplementary Figure S1C). Starting in October 2017, the first atomic resolution structures of the KATP channel formed by Kir6.2 and SUR1 were published (Lee et al., 2017; Li et al., 2017; Martin et al., 2017a,b; Wu et al., 2018). Thus, we compared the structural differences of our Kir3.2 based homology model with the new Kir6.2 templates. Due to the low RMSD of the structural alignments $(<1.5 \AA$, see Supplementary Figure S1B) we continued to use the Kir6.1 homology model 
based on the Kir3.2 template in subsequent molecular dynamics (MD) simulations.

\section{Unbiased $\mu s$ Time Scale MD Simulations Identify Putative RSG Binding Sites}

In an effort to identify the putative binding site of RSG (5-[[4-[2-[methyl(pyridin-2-yl)amino]ethoxy]phenyl]methyl]-

1,3-thiazolidine-2,4-dione), and its main metabolite N-desmethyl Rosiglitazone (5-[[4-[2-(pyridin-2-ylamino) ethoxy]phenyl]methyl]-1,3-thiazolidine-2,4-dione), N-RSG for short, full atomistic MD simulations were performed. Specifically, the binding was probed by adding 20 molecules $(10 \times \mathrm{S}$ conformer, $10 \times \mathrm{R}$ conformer, since the prescribed drug is a racemic mixture) randomly into the solvent, leading to an effective drug concentration of $\sim 170 \mathrm{mM}$. As seen in Figure 1, 13 ligands partition into the lipid membrane within $1.5 \mu \mathrm{s}$. Three out of 20 molecules occupied sites close to the protein for 1.3 - $1.5 \mu \mathrm{s}$ (see Table 1). The three major binding sites (Figure 2) identified are: close to the $\mathrm{PIP}_{2}$ binding site, denoted site $A$; the interface between two cytoplasmic domains (CTDs), denoted site $B$, and between the $\beta$-sheet $\beta D$ and the $\beta G-\alpha G$ loop, denoted site $\mathrm{C}$.

Binding site $\mathrm{A}$ is of particular interest since the ligand binds close to the transmembrane gate and the $\mathrm{PIP}_{2}$ binding site, a plausible location for extending long-lasting channel closures, as suggested by experiments ( $\mathrm{uu}$ et al., 2012). Binding includes mainly hydrophobic interactions with residue LEU57 and ILE60. Additionally, hydrophobic and hydrogen bond ( $\mathrm{HB}$ ) interactions with POPC lipid molecules are observed. Even though $\mathrm{PIP}_{2}$
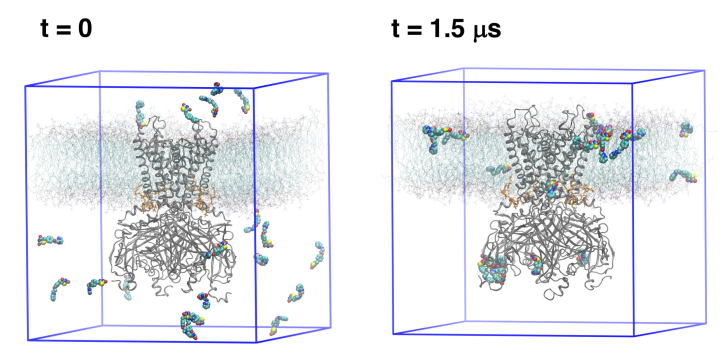

FIGURE 1 | Simulation setups: The first and last frame of free MD simulation. Protein (gray cartoon) is embedded in the lipid bilayer (cyan lines with red head groups). As a starting simulation setup $(t=0), 20$ ligands (shown as spheres) were randomly distributed in the solvent. After a $1.5 \mu \mathrm{s}$ MD simulation, the ligands either are bound to the protein or entered the lipid phase.

TABLE 1 | Three binding sites observed during unbiased MD simulations and their corresponding occupation time.

\begin{tabular}{lll}
\hline $\begin{array}{l}\text { Binding } \\
\text { site }\end{array}$ & $\begin{array}{l}\text { Binding time of ligand to } \\
\text { binding site }\end{array}$ & $\begin{array}{l}\text { Stereochemistry of } \\
\text { ligand }\end{array}$ \\
\hline A & $1.2 \mu \mathrm{s}(300 \mathrm{~ns}-1.5 \mu \mathrm{s})$ & R conformer \\
B & $1.5 \mu \mathrm{s}$ & S conformer \\
C & $1.3 \mu \mathrm{s}(200 \mathrm{~ns}-1.5 \mu \mathrm{s})$ & S conformer \\
\hline
\end{tabular}

All three ligands occupied the binding site for at least $1 \mu$ s and until the end of the simulation. Ligands migrate to binding site $A$ at 300 ns, to binding site $B$ right after the equilibration, and to binding site $C$ at 200 ns.

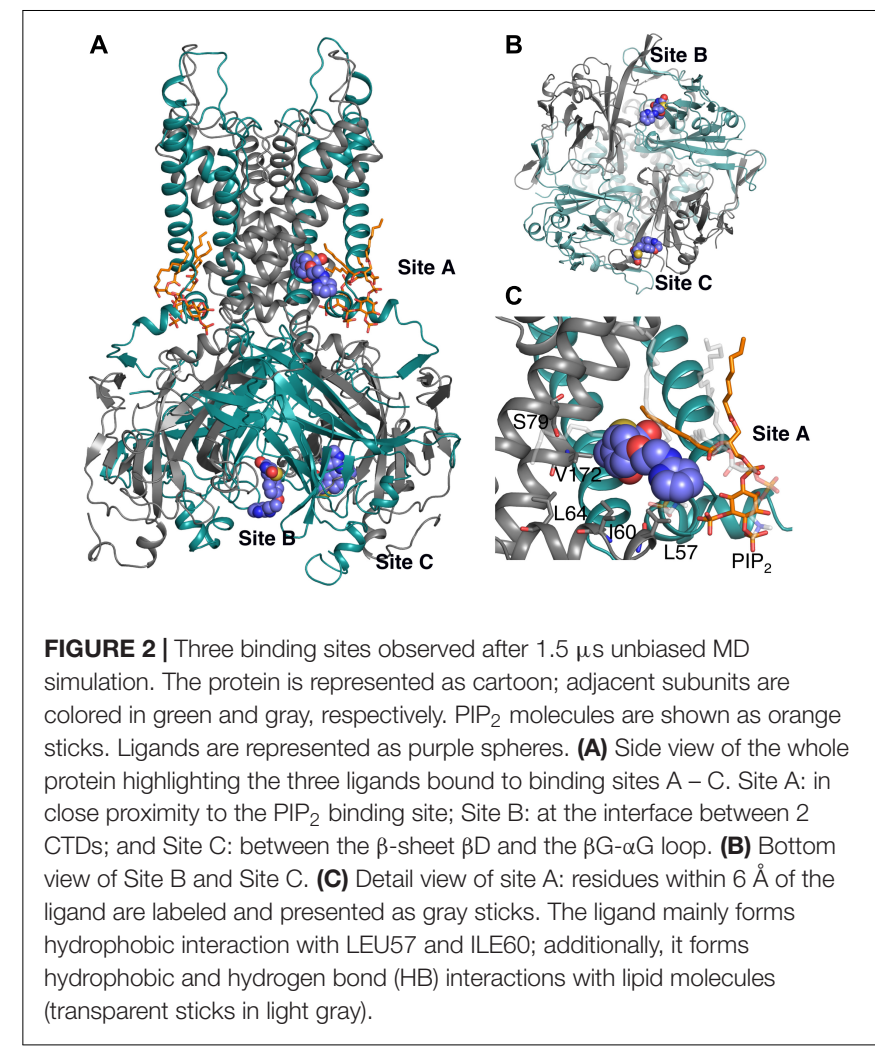

is within $5 \AA$ of ligand no specific interactions with RSG are observed. All residues within $6 \AA$ of ligand are shown in Figure 2C. Given the importance of this area for channel gating (Zhang et al., 2015) and the surface exposure of the binding site, we decided to perform a more exhaustive sampling of this region. We therefore used computationally less demanding docking simulations with both compounds, followed by $250 \mathrm{~ns}$ MD simulations of the best-scored pose for RSG, and 200 ns of the best-scored pose for N-RSG. This way, strengthened binding interactions (defined as increased accessible surface area: $0.9 \mathrm{~nm}^{2}$ for site A vs. $3 \mathrm{~nm}^{2}$ when using the best docking pose) were obtained. We refer to this new site A as site A_ref. Since binding sites B is in a more constrained pocket (see Supplementary Figure S6) and site $\mathrm{C}$ is in a region not shown to be relevant for channel gating, we did not further attempt to refine these two sites.

To further characterize the three binding sites, the potential of mean force (PMF) of the ligands at site A_ref, B and C, were calculated using umbrella sampling (US) simulations. As can be seen in Figure 3, the PMFs reveal clear differences between the three sites. Binding of RSG to site A_ref is most favorable. Since PMF calculations reveal shallow binding for ligands bound at sites $\mathrm{B}$ and $\mathrm{C}$, we did not further investigate these two binding sites. Nevertheless, ligand binding site $B$, might be potentially interesting, since intersubunit interactions in this region have been shown previously to be important for the inactivation process in Kir6.2 channels (Lin et al., 2003; Borschel et al., 2017) and could be further investigated in future studies. 


\section{PMFs at binding sites}

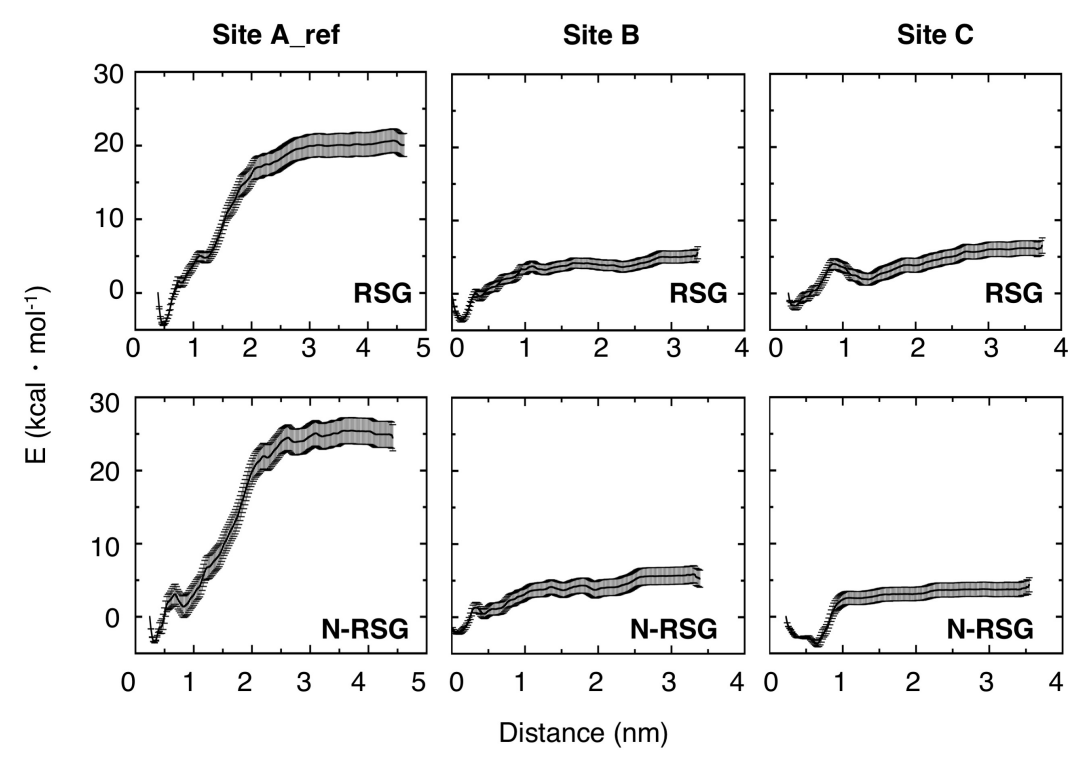

FIGURE 3 | Potential of Mean Forces (PMFs) derived from US for both RSG and N-RSG at the three binding sites. The energy profiles are depicted including their standard deviations. The WHAM histograms are shown in Supplementary Figure S4. Site A_ref shows higher binding affinity for both, RSG and N-RSG, compared to the other binding sites.

\section{Detailed Characterization of Binding Site A_ref}

The interactions of RSG and N-RSG at site A_ref over 200 ns of the $\mathrm{MD}$ simulations were quantified using interaction matrices as described in the methods section. Ligands were decomposed as five parts (Figure $\mathbf{4 A}$ and Supplementary Figure S2): the pyridine (Ring $\mathrm{A}$ ), the benzene (Ring $\mathrm{B}$ ), the thiazolidinedione (Ring C), the linker connecting pyridine and benzene (Linker D), and the linker connecting benzene and thiazolidinedione (Linker E). RSG mainly formed hydrophobic interactions with the binding site throughout the trajectory. More than $75 \%$ of the frames contain hydrophobic interactions between the Ring $A$ and residue PHE76, VAL172, and MET173, and between the Linker E and TRP69. Residues LEU64, ILE75, PHE80, ILE168, and ILE169 also frequently formed hydrophobic interactions with RSG (Figures 4B,D). The interaction map of N-RSG molecule reveals a similar trend indicating mainly hydrophobic interactions with the binding site (see Supplementary Figure S2). Both ligands also form HBs with POPC lipid molecules, which are not included in the interaction map calculations (RMSD plots of ligands are shown in Figure 4C and Supplementary Figure S2C). For relative location of binding site A_ref with respect to the SUR subunit, see Supplementary Figure S7.

\section{Structure Based Dynamic Pharmacophore Models of RSG Binding to Site A_ref}

Understanding the inhibition mechanisms of the pore-forming Kir6.1 subunit could be a first step to develop novel blockers for the treatment of rare disease causing mutations (e.g., Cantú mutations V64M), which are not amenable for sulfonylurea therapy (Cooper et al., 2017). In line with this reasoning we constructed dynamic structure-based pharmacophore models and screened for hits in DrugBank (Law et al., 2014), which contains all marketed drugs, by using the common hits approach (CHA) (Wieder et al., 2017). Structure-based pharmacophore models were generated using 5,000 frames from the MD simulation, which included the lipid bilayer but omitted solvent molecules. Pharmacophore models, which contain common pharmacophore features and identical involved ligand atoms, are considered as one representative pharmacophore model. Five representative pharmacophore models (Model $1-5$ ) were observed from the frames (shown in Supplementary Figure S3). Model 1 was observed most frequently (>95\%, 4,776 times out of 5,000 of frames). The other four models appeared in less than $5 \%$ of the frames. All models share two hydrophobic features formed with pyridine and benzene in the ligand. Model 1 contains one additional $\mathrm{HB}$ donor with the $\mathrm{NH}$ moiety of thiazolidinedione. Model 2 only contains the shared hydrophobic features. Model 3 and Model 4 also share the same hydrophobic features plus one $\mathrm{HB}$ donor and one $\mathrm{HB}$ acceptor. Model 5 comprises the shared hydrophobic features and one $\mathrm{HB}$ acceptor. All five pharmacophore models were used to screen DrugBank. The top ranked hitlist for binding site A_ref is shown in Table 2.

After careful assessment of the main-targets and diseases intended to treat with the compounds and the side effects (listed in Table 3), we selected Travoprost, Betaxolol, and Ritodrine (Docking poses are shown in Supplementary Figure S5) for further testing, since these compounds are not known to cause cardiac side effects or hypoglycemia. 


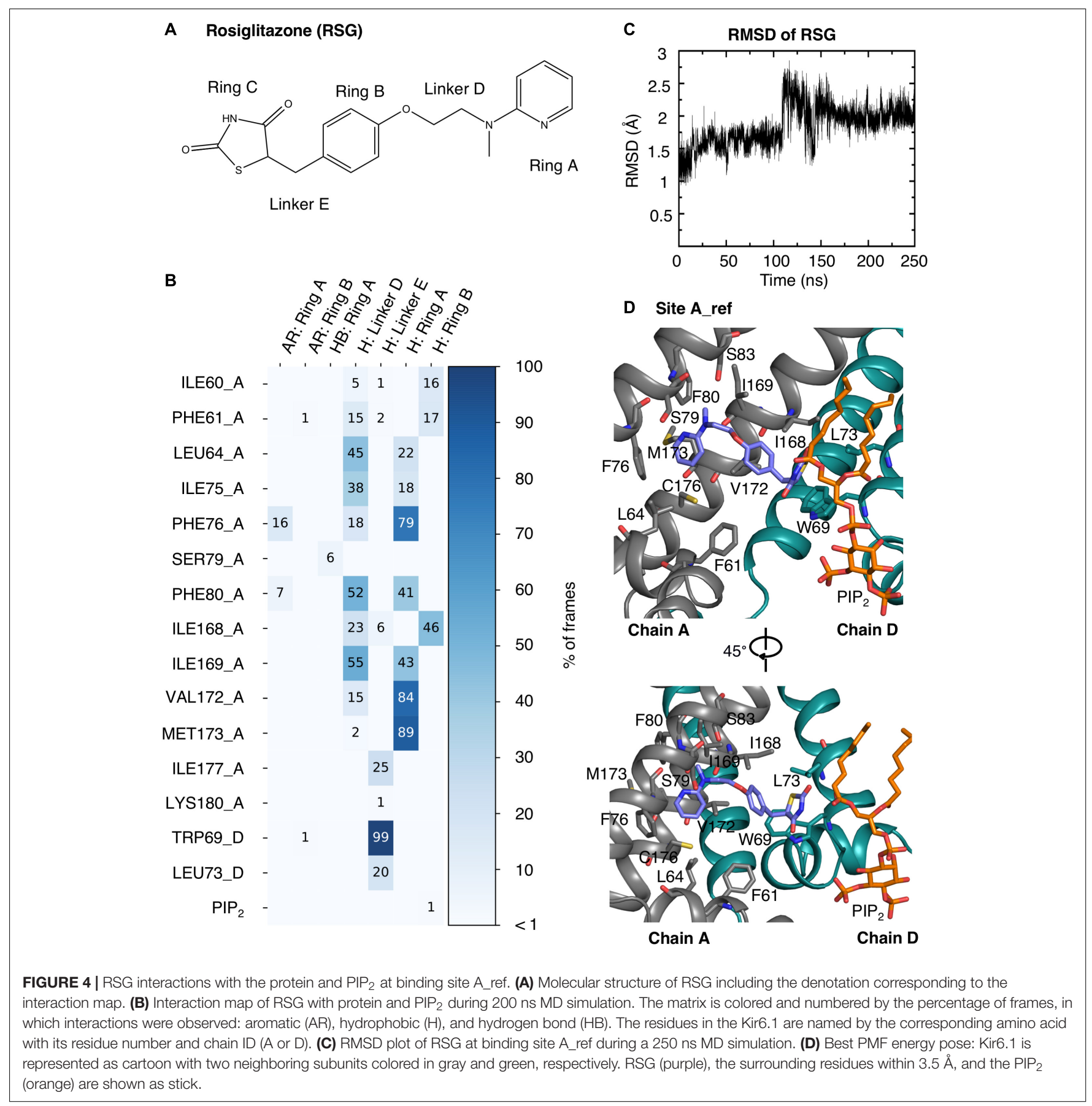

\section{Inhibition of Kir6.2/SUR2A by Travoprost, Betaxolol, and Ritodrine}

From earlier work it was established that in the absence of pharmacological activation, Kir6.1/SUR2A channels yield very low current amplitude which hampers efficacy assessment of blockers (Cooper et al., 2014). Therefore, Travoprost, Betaxolol, and Ritodrine [three top ranked hits (Table 2)] were tested for Kir6.2/SUR2A inhibition instead, using the inside/out mode on HEK293T cell derived excised membrane patches. Travoprost $\left(\mathrm{IC}_{50}\right.$ outward $=2.46 \pm 0.52 \mu \mathrm{M}$;
Hill coefficient 0.71; IC $\mathrm{IC}_{50}$ inward $=2.30 \pm 1.26 \mu \mathrm{M}$; Hill coefficient 0.65 ) dose-dependently inhibited inward and outward current components of $\mathrm{I}_{\text {Kir6.2/SUR2A }}$ whereas Betaxolol ( IC $_{50}$ outward $=22.06 \pm 2.47 \mu \mathrm{M}$; Hill coefficient 0.89 ) and Ritodrine $\left(\mathrm{IC}_{50}\right.$ outward $=7.09 \pm 0.45 \mu \mathrm{M}$; Hill coefficient 0.86) markedly and dose-dependently inhibited the outward component (Figure 5). Betaxolol and Ritodrine induced rectification behavior of the channel, i.e., outward current was more strongly inhibited than inward current (Figure 5B). This induction of rectification is in contrast with inhibition 
TABLE 2 | Top ranked hit-list for binding site A_ref.

\begin{tabular}{lllc}
\hline DrugBank ID & Generic name & CHA score & $\begin{array}{c}\text { Number of active } \\
\text { pharmacophores }\end{array}$ \\
\hline DB08907 & Canagliflozin & 2.7417 & $3 / 5$ \\
DB01095 & Fluvastatin & 2.7246 & $3 / 5$ \\
DB09351 & Levobetaxolol & 2.7035 & $3 / 5$ \\
DB00917 & Dinoprostone & 1.8892 & $2 / 5$ \\
DB00195 & Betaxolol & 1.862 & $2 / 5$ \\
DB00841 & Dobutamine & 1.852 & $2 / 5$ \\
DB00287 & Travoprost & 1.8516 & $2 / 5$ \\
DB00938 & Salmeterol & 1.8475 & $2 / 5$ \\
DB00179 & Masoprocol & 1.8458 & $2 / 5$ \\
DB00867 & Ritodrine & 1.8104 & $2 / 5$ \\
DB09198 & Lobeglitazone & 1.8102 & $2 / 5$ \\
DB04855 & Dronedarone & 1.8096 & $2 / 5$ \\
DB06817 & Raltegravir & 1.805 & $2 / 5$ \\
DB09570 & Ixazomib & 1.8038 & $2 / 5$ \\
DB01346 & Quinidine barbiturate & 1.8019 & $2 / 5$ \\
DB00204 & Dofetilide & 1.7997 & $2 / 5$ \\
DB01240 & Epoprostenol & 1.7992 & $2 / 5$ \\
DB00662 & Trimethobenzamide & 1.7935 & $2 / 5$ \\
DB08875 & Cabozantinib & 1.7838 & $2 / 5$ \\
DB09330 & Osimertinib & 1.7275 & $2 / 5$ \\
\hline
\end{tabular}

The hit-list was established by screening the dynamic pharmacophore models to the DrugBank database. Top 20 approved drugs ranked by CHA score are proposed in the displayed hit-list.

characteristics of Travoprost and RSG. Similar findings have been made with Pentamidine and Pentamidine-Analog-6 (De Boer et al., 2010; Takanari et al., 2013). These structurally related compounds bind to the same site in the Kir2.1 channel, but whereas Pentamidine induces channel rectification (De Boer et al., 2010), Pentamidine-Analog-6 inhibited both inward and outward current with similar efficacy (Takanari et al., 2013). Despite the clear block of Kir6.2 - KATP channels by Travoprost, Betaxolol, and Ritodrine, these drugs do not show KATP channel related clinical effects, however, it has to be kept in mind that the former two drugs are not applied systemically.

\section{Further Support of RSG Binding to Site A_ref}

Experimental data from Yu et al. (2012) revealed that RSG binding to inward rectifier potassium channels is Kir6.x specific. Electrophysiology measurements on Kir1.1, Kir2.1, and Kir4.1 channels showed that these channels are insensitive to RSG. Thus, we performed a multiple sequence alignment of these channels and evaluated the conservation of the predicted binding site residues. As shown in Figure 6, differences between Kir6.x and members of other Kir channels at site A_ref can be found at positions 64 (LEU vs. VAL/CYS/PHE), 79 (SER vs. ALA/THR), 172 (VAL/ILE vs. PHE), and 176 (CYS vs. ALA/THR). Of particular interest is position 172, which contains a bulky phenylalanine side chain in non-Kir6.x channels, which would prevent RSG from binding in a similar mode in these channels. Experimental mapping of the binding site has not been performed, possibly due to challenges measuring Kir6.1 subunits (Cooper et al., 2014). Nevertheless, mutational data on the closely related Kir6.2 channel supports that residues in the binding area are critical for normal channel gating (Zhang et al., 2015). Interestingly, two Cantú disease causing gain-of-function mutations (V65M, C176S) (Brownstein et al., 2013; Cooper et al., 2014) are in close proximity to binding site A_ref, further supporting the importance of this region for gating. A further, indirect validation of the binding site was gained by correctly identifying novel hits in DrugBank, based on the in silico predicted structure-based drugprotein interactions.

\section{Suggestions for Experimental Validation of the Binding Site}

Our modeling predictions suggest that mutating position VAL172 to PHE should decrease or prevent binding of RSG and its main metabolite N-RSG. Unfortunately, mutating the equivalent position in Kir6.2 (ILE162) to PHE does not produce functional channels (Piao et al., 2001), preventing experimental validation of this prediction. Since the binding site is very close to the $\mathrm{PIP}_{2}$ molecule, interference of $\mathrm{PIP}_{2}$ interactions with the channel are likely. Previous studies on other Kir channels, support drug $\mathrm{PIP}_{2}$ interference for drugs such as carvedilol and ivermectin (Kikuta et al., 2006; Ferrer et al., 2011; Chen et al., 2017) or the anti-cancer agent gamboic acid (Scherer et al., 2017). For a recent review see (Heyden et al., 2013).

Other means of validation could include $\mathrm{Rb}^{+}$flux measurements or transfer of the binding pocket to another inward rectifier channel such as Kir2.1, which has been shown to be insensitive to RSG. A real advancement toward understanding inhibition of Kir6 channels would, however, require obtaining co-crystals of KATP channels bound to RSG or other inhibitors. Further, Kir6.1 containing electrophysiology-based screening assays need to be developed to progress CS research.

\section{Proposed Mechanism of Drug Action}

RSG binds at the interface between two subunits, very close to $\mathrm{PIP}_{2}$, an essential gating modulator of inward rectifier channels. It is conceivable that the drug interferes with normal channel activation, possibly via "blocking" the activation gate and/or via hindering normal lipid modulation of channels. In line with this reasoning, we observed frequent $\mathrm{HBs}$ to lipid molecules in our simulations. Further simulations, using different lipid types will be necessary in the future to investigate this possibility. In addition, the predicted binding site A_ref is in close proximity of two previously identified gain-offunction mutations causing Cantú disease [V65M and C176S (Brownstein et al., 2013; Cooper et al., 2014)]. So far 100 ns MD simulations on these two mutations have been performed (Cooper et al., 2017), revealing no changes in this region. Thus, in order to investigate if RSG or the newly identified inhibitors might be able to counterbalance the gating disturbance effects of Cantú mutations, we determined dose-response effects of currents mediated by C166S Kir6.2, which is homologs to C176S in Kir6.1. 
TABLE 3 | Indication, description, and relevant side effect of the top ranked hit-list compounds at binding site A_ref.

\begin{tabular}{|c|c|c|c|}
\hline DrugBank ID & Generic name & Indication / Description & Relevant side effect \\
\hline DB08907 & Canagliflozin & Anti-diabetic (sodium-glucose transport protein inhibitor) & $\begin{array}{l}\text { Fungal genital infection fungal, Urinary tract infection, } \\
\text { Nausea }\end{array}$ \\
\hline DB01095 & Fluvastatin & Antilipemic (inhibits HMG-CoA reductase) & Myotoxicity \\
\hline DB09351 & Levobetaxolol & $\begin{array}{l}\text { Glaucoma or ocular hypertension (selective } \\
\text { beta-1-adrenergic receptor antagonist) }\end{array}$ & $\begin{array}{l}\text { Burning or stinging in eye drainage from the eye redness; } \\
\text { Swelling, and/or itching of eye and eyelid }\end{array}$ \\
\hline DB00917 & Dinoprostone & $\begin{array}{l}\text { Cervix preparation and induction for labor (naturally } \\
\text { occurring prostaglandin E2, PGE2) }\end{array}$ & $\begin{array}{l}\text { Fetal heart rate; Fetal distress syndrome; Uterine } \\
\text { hypertonus; Failed induction of labor }\end{array}$ \\
\hline DB00195 & Betaxolol & $\begin{array}{l}\text { Glaucoma or ocular hypertension (cardioselective } \\
\text { beta-1-adrenergic antagonist) }\end{array}$ & $\begin{array}{l}\text { Fatigue; Dyspepsia; Headache; Dizziness; Arthralgia; } \\
\text { Myalgia; Insomnia; Diarrhea }\end{array}$ \\
\hline DB00841 & Dobutamine & $\begin{array}{l}\text { Cardiac stimulant after myocardial infarction or open heart } \\
\text { surgery (beta-1 agonist) }\end{array}$ & Angina pectoris; Chest pain; Headache \\
\hline DB00287 & Travoprost & $\begin{array}{l}\text { Glaucoma or ocular hypertension (ophthalmic solution, } \\
\text { synthetic prostaglandin F2alpha analog) }\end{array}$ & $\begin{array}{l}\text { Hyperaemia; Iris hyperpigmentation; Eye disorder; Ocular } \\
\text { hyperaemia; Eye pruritus; Eye pain and irritation; Ocular } \\
\text { discomfort }\end{array}$ \\
\hline DB00938 & Salmeterol & $\begin{array}{l}\text { Asthma and chronic obstructive pulmonary disease } \\
\text { (long-acting beta2-adrenergic receptor agonist) }\end{array}$ & $\begin{array}{l}\text { Headache; Musculoskeletal pain; Pallor; Sinus congestion; } \\
\text { Hypersensitivity Tremor; Palpitations }\end{array}$ \\
\hline DB00179 & Masoprocol & $\begin{array}{l}\text { Actinic keratoses (precancerous skin growths that can } \\
\text { become malignant if left untreated; lipoxygenase inhibitor) }\end{array}$ & Antineoplastic \\
\hline DB00867 & Ritodrine & $\begin{array}{l}\text { Treatment and prophylaxis of premature labor (beta-2 } \\
\text { adrenergic agonist) }\end{array}$ & Increase in heart rate; Arrhythmia \\
\hline DB09198 & Lobeglitazone & $\begin{array}{l}\text { Antidiabetic drug (peroxisome proliferator-activated } \\
\text { receptor (PPAR) alpha and gamma) }\end{array}$ & Not approved to use \\
\hline DB04855 & Dronedarone & Class III antiarrhythmic & $\begin{array}{l}\text { Pulmonary fibrosis; Interstitial lung disease; } \\
\text { Leukocytoclastic vasculitis }\end{array}$ \\
\hline DB06817 & Raltegravir & Antiretroviral treatment of HIV infection (integrase inhibitor) & Malnutrition; Mental disorder \\
\hline DB09570 & Ixazomib & Multiple myeloma (proteasome inhibitor) & Antineoplastic; Hepatotoxic \\
\hline DB01346 & Quinidine barbiturate & - & Obsolete \\
\hline DB00204 & Dofetilide & Class III antiarrhythmic (IKr inhibition) & Torsades de pointes \\
\hline DB01240 & Epoprostenol & $\begin{array}{l}\text { Primary pulmonary hypertension (prostaglandin I2, } \\
\text { vasodilator, inhibition of platelet aggregation) }\end{array}$ & Headache; Hypotension; Nausea \\
\hline DB00662 & Trimethobenzamide & Antiemetic (D2 receptor antagonist) & Parkinsonism; Tremors \\
\hline DB08875 & Cabozantinib & $\begin{array}{l}\text { Metastatic medullary thyroid cancer, renal cell carcinoma } \\
\text { (non-specific tyrosine kinase inhibitor) }\end{array}$ & $\begin{array}{l}\text { Gastrointestinal fistulas and perforations; Potentially fatal } \\
\text { hemoptysis and gastrointestinal hemorrhage }\end{array}$ \\
\hline DB09330 & Osimertinib & $\begin{array}{l}\text { Non-small cell lung cancer (epidermal growth factor } \\
\text { receptor tyrosine kinase inhibitor) }\end{array}$ & Interstitial lung disease \\
\hline
\end{tabular}

All information is collected from SIDER database (Kuhn et al., 2010, 2016) and DrugBank (Law et al., 2014).

\section{Cantú Mutations C166S (Kir6.2) and S1020P (SUR2A) Are Inhibited by RSG, Ritodrine, Travoprost, and Betaxolol}

Since CS C176S mutant is in close proximity of the predicted binding site A_ref, we performed inside/out measurements on Kir6.2 C166S, the homologs mutation of Kir6.1 C176S, with RSG and the newly identified drugs Travoprost, Betaxolol, and Ritodrine. As shown in Figure 7 all drugs dose-dependent inhibit outward current, having IC $\mathrm{I}_{50}$ similar as WT channels (RSG: WT $25.98 \pm 1.49 \mu \mathrm{M}$ vs. C166S $34.88 \pm 2.34 \mu \mathrm{M}$ n.s.; Ritodrine: WT $7.09 \pm 0.45 \mu \mathrm{M}$ vs. C166S $10.42 \pm 0.87 \mu \mathrm{M}$ n.s.; Betaxolol: WT $22.06 \pm 2.47 \mu \mathrm{M}$ vs. $41.16 \pm 2.89 \mu \mathrm{M}$ n.s.) except for Travoprost (WT $2.46 \pm 0.52 \mu \mathrm{M}$ vs. $14.82 \pm 2.16 \mu \mathrm{M}, p<0.05$ ).

Since the majority of Cantú mutations have been identified in the SUR2A subunits, we also tested the inhibitors on currents mediated by the S1020P SUR2A mutation. Again, mutant channels were sensitive for all for compounds with outward current IC $_{50}$ values (Rosiglitazone: $25.38 \pm 4.24 \mu \mathrm{M}$; Ritodrine:
$6.77 \pm 0.49 \mu \mathrm{M}$; Betaxolol: $29.51 \pm 3.78 \mu \mathrm{M})$ not significantly different from WT channels except for Travoprost $(10.99 \pm 1.28 \mu \mathrm{M}, p<0.05$ vs. WT $)$.

Interestingly, previous studies on Kir6.2-C166S revealed increased open probability, reduced ATP sensitivity of Kir6.2 $\Delta \mathrm{C}$ and reduced tolbutamide sensitivity when expressed with SUR1 (Trapp et al., 1998). Since the three identified inhibitors are active on mutant channels with increased open probability, it would be interesting to test if the newly identified inhibitors would also display reduced sensitivity toward SUR1, or if the difference originates from the binding to the different subunits (Kir6 vs. SUR subunit). This is of particular interest, since mutation C166Y also displays reduced sensitivity for tolbutamide (Babiker et al., 2016) and DEND (developmental delay and neonatal diabetes) patients with this mutation are glibenclamide unresponsive (Della Manna et al., 2008). Thus, the compounds studied here could be of great interest to these patients, if efficacious on C166Y mutant channels co-expressed with SUR1. 
A

Travoprost<smiles>CC(CCC1C(C)CC(C)C1C/C=C\CCCC(=O)OC(C)C)COC1CCCC(C(C)(C)C)C1</smiles>

Betaxolol<smiles>CC(CNC(C)C)COc1ccc(CCOCC2CC2)cc1</smiles>

Ritodrine

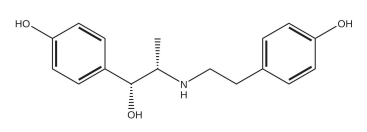

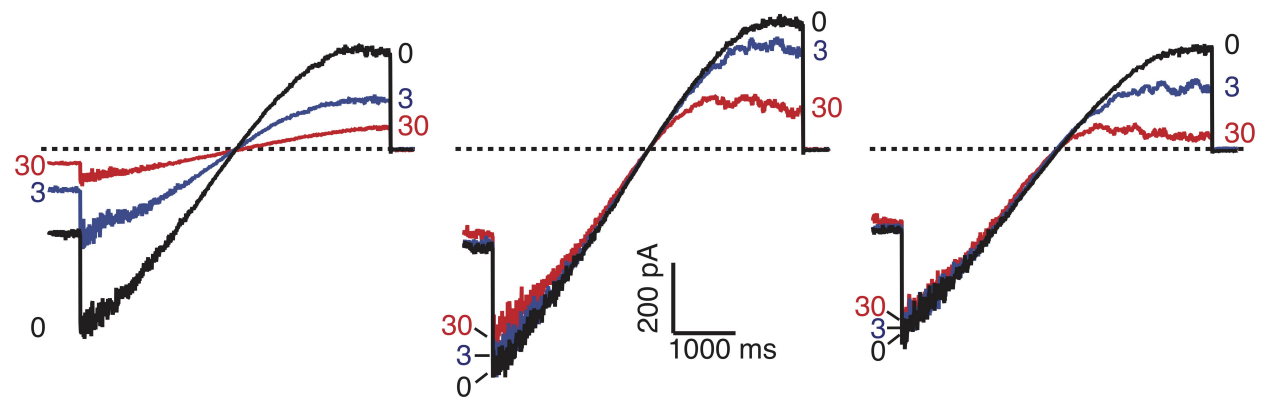

B

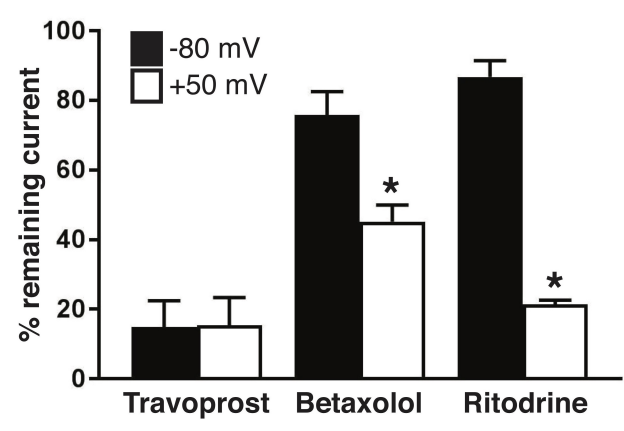

C

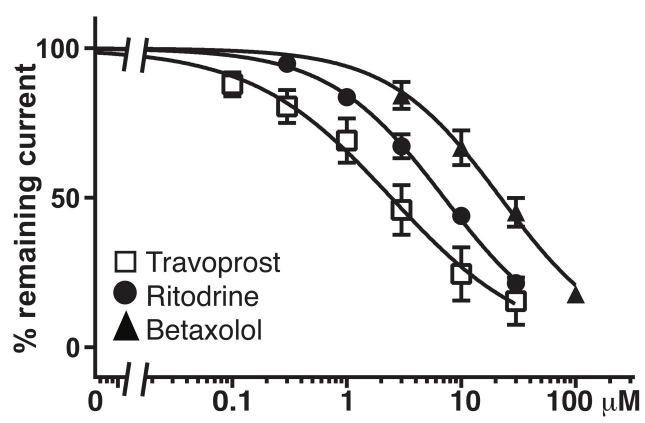

FIGURE 5 | Inhibition of Kir6.2/SUR2A carried IKATP by Travoprost, Betaxolol, and Ritodrine. (A) Current traces of Kir6.2/SUR2A channels in the inside-out orientation exposed to Travoprost, Betaxolol, or Ritodrine at the indicated drug concentrations (0, 3 and $30 \mu \mathrm{M})$. Dotted horizontal line at 0 pA. (B) Normalized block of inward (black bars, at $-80 \mathrm{mV}$ ) and outward (open bars, at $+50 \mathrm{mV}$ ) currents with $30 \mu \mathrm{M}$ of the indicated drug. ${ }^{*} P<0.001$ (paired T-test, inward vs. outward; $n=8, n=11$, and $n=9$ for Travoprost, Betaxolol, and Ritodrine, respectively. (C) IC $\mathrm{I}_{50}$ curves of outward components of Kir6.2/SUR2A in response to different concentrations of Travoprost (open squares; $n=8$ ), Betaxolol [black triangles; $n=11$ or $n=7(100 \mu \mathrm{M})$ ] and Ritodrine [black circles; $n=9$ (control and $1 \mu \mathrm{M}), n=8$ $(0.3 \mu \mathrm{M})$, or $n=7(3,10,30 \mu \mathrm{M})]$. Data were fitted with Hill equation to estimate the $\mathrm{IC}_{50}$ values. Data in panels $\mathrm{b}$ and $\mathrm{c}$ are shown as mean $\pm \mathrm{SEM}$. The data in panel $\mathrm{B}$ are extracted from the ramp recordings similar to traces as shown in panel $\mathrm{A}$.

\begin{tabular}{|c|c|c|c|c|}
\hline \multirow{2}{*}{\multicolumn{2}{|c|}{$\begin{array}{cc}\text { Chain A SH } \\
61 \quad 64\end{array}$}} & Chain A TM1 & Chain A TM2 & Chain D TM1 \\
\hline & & $\begin{array}{llll}76 & 79 & 80 & 83\end{array}$ & 168169172173176 & $69 \quad 73$ \\
\hline Kir6.1 & | F T T LV 65 & I F TMS F L C SW 84 & L I I NA VM L GC | 177 & KWRH T LV 74 \\
\hline Kir1.1 & I $\mathbf{W} \top \top \mathrm{V} L 73$ & | F | TAF L GSW 92 & VI I NSFMCGA | 178 & KWR Y K M T 82 \\
\hline Kir2.1 & | F T TCV 77 & I $\mathrm{F} C L \mathrm{AF} \vee \mathrm{LSW} 96$ & C I I DAF I | GAV179 & RWRWM LV 86 \\
\hline Kir4.1 & $\llcorner W \top T F \mid 60$ & LF S A T F A G TW 79 & TI LE | F I TGTF 165 & QWR Y KL L 69 \\
\hline
\end{tabular}

Whereas this proof-of-concept study reveals the general feasibility of inhibiting CS mutants with these drugs, the efficacy of the identified drugs for glibenclamide-insensitive mutant channels remains to be tested in future studies.

\section{CONCLUSION AND LIMITATIONS}

Understanding the molecular mechanisms of inhibition of Kir6.x channels is critical in paving the way to develop novel blockers, 

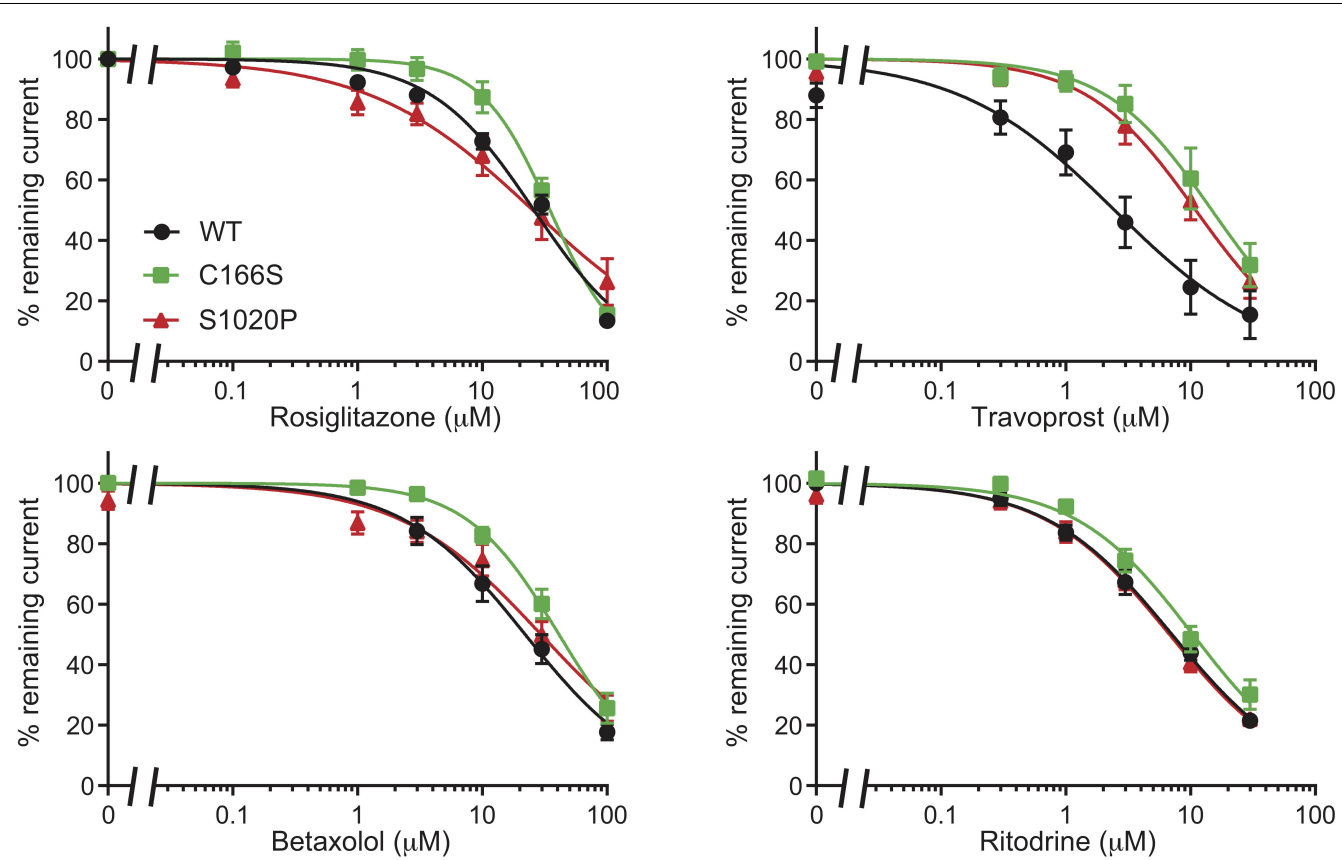

FIGURE 7 | Inhibition of C166S (Kir6.2) and S1020P (SUR2A) by Rosiglitazone, Travoprost, Betaxolol, and Ritodrine. IC 50 curves of outward components of Kir6.2/SUR2A (WT, C166S Kir6.2, and S1020P SUR2A) in response to different concentrations of Rosiglitazone, Travoprost, Betaxolol, and Ritodrine. N-values are: WT, C166S, and S1020P, respectively: Rosiglitazone $n=8,8,6$; Travoprost $n=8,7,11$; Betaxolol $n=11,7,7$; and Ritodrine $n=9$, 8, 7. Data were fitted with Hill equation to estimate the $\mathrm{IC}_{50}$ values. Data are shown as mean $\pm \mathrm{SEM}$.

useful for the treatment of channelopathies such as neonatal diabetes (Remedi et al., 2017) or CS (Brownstein et al., 2013; Cooper et al., 2014). Further, our study provides insights into how RSG might exert its cardiovascular side effects, via interfering with its gating mechanism. We performed unbiased MD simulations on the microsecond time scale of the pore forming Kir6.1 model with RSG randomly placed in the solvent. After identification of a putative RSG binding site, we constructed dynamic pharmacophore models using the recently introduced CHA and screened for hits in DrugBank, which contains all drugs available on the market. Functional testing confirmed three new high affinity blockers, with different chemical scaffolds (see Figure 5). The identified compounds (see Table 2) provide an important first starting point for developing novel therapies for rare diseases such as CS.

Although this proof-of-concept study demonstrations the general feasibility of our computational approach to identify novel Kir6.x inhibitors, clinical efficacy and safety remain to be tested in the future. In particular, even though the side-effect profile of approved drugs is in principal well defined, the suitability for repurposing such drugs to pharmacologically correct CS associated gain-of-function mutations awaits further studies. Further, it is currently not foreseeable, which clinical features of CS could be treated/corrected by inhibiting KATP channels.

Another limitation is the inability to measure large enough Kir6.1 currents (in the absence of activators such as pinacidil) to reliably assess drug affinity. This prevents addressing the specificity of Kir6.1 vs. Kir6.2 inhibitors. In our opinion, it will require joint efforts from multiple institutes to obtain favorable cell lines, expression constructs, forward trafficking enhancing factors and patch-clamp protocols, in order to move the field forward.

Nevertheless, this study provides novel insights into the structural basis of Kir6.x channel block, could provide a solid basis for future studies and may have broader implications for the molecular pharmacology of Kir6 channels in general.

Finally, this study provides interesting insights into the polypharmacology of betaxolol, ritodrine and travoprost, since none of these drugs have been linked to KATP channel inhibition before.

\section{MATERIALS AND METHODS}

\section{Homology Modeling}

At the beginning of this study, no atomic resolution structure of a KATP channel was available. Thus, a Kir6.1 homology model in the closed state was built using the crystal structure of Kir3.2 (PDB code: 3SYA (Whorton and MacKinnon, 2011), $2.98 \AA$ resolution) as template with the program Modeller9.11 (Martí-Renom et al., 2000). The sequence identity between Kir6.1 and Kir3.2 is $48.36 \%$. The sequence alignments can be found in Supplementary Figure S1A. Comparison of the Kir3.2 template with recent available Kir6.2 structures reveal that the structures are highly similar with RMSD values below $1 \AA$ (comparing the transmembrane domains). The structural alignments, generated with the 
Swiss-PDB-viewer (Guex and Peitsch, 1997) are shown in Supplementary Figure S1B.

\section{Simulations}

MD simulations were performed using Gromacs5.1 (Abraham et al., 2015) and the Amber99sb force field (Hornak et al., 2006). The Kir6.1 protein was embedded into the palmitoyloleoylphosphatidylcholine (POPC) lipid bilayer with four $\mathrm{PIP}_{2}$ molecules bound to the channel, as described previously (Lee et al., 2016). PIP $_{2}$ was parameterized using the Hartree-Fock geometry optimization with the $6-31 G^{*}$ basis set (Frisch et al., 2013). POPC parameters were taken from Berger lipids parameters (Berger et al., 1997). The system was solvated using the SPCE water model (Berendsen et al., 1987; Kusalik and Svishchev, 1994) and $150 \mathrm{mM} \mathrm{KCl}$ were added to the solvent. To keep the selectivity filter stable, five $\mathrm{K}^{+}$ions were placed at sites S0 to S4. The force field parameters of the ligand were generated and optimized with Gaussian09 (HF/6-31G* basis set) and antechamber (Wang et al., 2004, 2006). Ten R-form and ten $S$-form ligands were randomly placed in the solvent of the system. The algorithm to integrate Newton's equation of motion was leap-frog, with a time step of 2 fs. The LINCS algorithm (Hess et al., 1997) was used to constrain all bonds. The cutoff-scheme for neighbor searching used Verlet (Verlet, 1967) within $1 \mathrm{~nm}$ and updated the list every $10 \mathrm{fs}$. The electrostatics and VdW interactions were measured with the particle-mesh Ewald (PME) method (Darden et al., 1993), using a cut-off of $1 \mathrm{~nm}$ and Fourier spacing of $0.16 \mathrm{~nm}$. Temperature coupling used the V-rescale method (Bussi et al., 2007) at a reference temperature of $310 \mathrm{~K}$ and time constant $0.1 \mathrm{ps}$. The pressure was kept constant at $1 \mathrm{bar}$ by using the Parrinello-Rahman barostat algorithm (Parrinello and Rahman, 1981) with a coupling constant of 2 ps. The system was minimized with the steepest descent algorithm, followed by a 6 ns equilibration simulation. $1.5 \mu$ s unbiased MD simulations were performed to detect the ligand binding sites. Additionally, 250 ns and $200 \mathrm{~ns} \mathrm{MD}$ simulations were run from the best docking poses of RSG and N-RSG, respectively.

\section{Docking}

RSG was docked at the putative binding site identified from unbiased MD simulations, using the program Gold4.0.1 (Jones et al., 1997). The binding sites identified in the $1.5 \mu$ s free MD simulations were used as starting point and the radius was set to $20 \AA$. 100,000 operations of the GOLD genetic algorithm were used to dock the compounds with the ChemPLP scoring function.

\section{Umbrella Sampling (US)}

In order to estimate the ligand binding affinity, we performed US at each binding site. Ligands were firstly pulled into the solvent using the pull code in GROMACS by applying a harmonic biasing force between the center of mass (COM) of ligand and the COM of binding site (defined by residues within $5 \AA$ of the ligand). The initial systems were taken from the last frames of the MD simulations for binding sites A_ref, B and C. To ensure that the ligands were pulled along the reaction coordinates fully into the solvent area, a harmonic force of $1,000 \mathrm{~kJ} /\left(\mathrm{mol} \cdot \mathrm{nm}^{2}\right)$ was applied for most of the pulling simulations. In cases, where the ligand displayed high mobility during the pulling trajectories, the harmonic force was increased to $2,000 \mathrm{~kJ} /\left(\mathrm{mol} \cdot \mathrm{nm}^{2}\right)$. Starting configurations for US were chosen from the pulling trajectories by taking steps every $0.1 \mathrm{~nm}$ along the reaction coordinates. Several intermediate windows were added if the adjacent US windows did not overlap sufficiently. Harmonic forces of 500, $1,000,2,000$, or $3,000 \mathrm{~kJ} /\left(\mathrm{mol} \cdot \mathrm{nm}^{2}\right)$ were applied to restrict the ligands during US sampling. For each window, a 10 ns simulation was performed, excluding the first $1 \mathrm{~ns}$ as equilibration. In total, 242 windows were simulated. Thus, in total, $2.42 \mu \mathrm{s}$ simulations were performed to obtain good US window overlaps (Supplementary Figure S4). The PMF were calculated by using weighted histogram analysis method (WHAM) (Hub et al., 2010) and the statistical errors were estimated by 100 times bootstrap analysis (Efron, 1979). A more detailed description about the US method can be found in the Supplementary Methods.

\section{Pharmacophore Modeling}

The recent published CHA (Wieder et al., 2017) was applied to construct dynamic pharmacophore models and to generate a hitlist by virtual screening in DrugBank (Law et al., 2014). The CHA is implemented by LigandScout 4.10 (Wolber and Langer, 2005).

5,000 snapshots were extracted from the last 100 ns MD simulation of RSG at binding site A_ref and used as input for the CHA. For each snapshot, a pharmacophore model was built by considering the ligand interactions with protein and lipids. Water molecules were discarded during the pharmacophore generation. Pharmacophore features (mainly including hydrophobic interactions, $\mathrm{HB}$ donor/acceptor, aromatic ring, ionizable area, etc.) and constrains were defined as described in detail in the LigandScout user manual (LigandScout User Manual, 2010).

Representative pharmacophore models were obtained by merging all identical features, extracted from the 5,000 frames. In the end, five representative pharmacophore models were used for virtual screening against DrugBank4.0 (Law et al., 2014; see Supplementary Figure S3). The molecules in DrugBank were prepared as libraries for virtual screening using the LigandScout command line tool idbgen. Conformers for each molecule in the database were generated using the icon best option in idbgen; this option produces a maximum number of 200 conformations for each molecule processed. The CHA produced a ranked hit-list for the binding site. The approved drugs that fits at least two of the five representative pharmacophore models were proposed in the final hit-list shown in Table 2.

\section{Interaction Map}

The interactions of RSG and N-RSG at site A_ref (only protein and $\mathrm{PIP}_{2}$ were considered) over the 200 ns MD simulations were analyzed and quantified by interaction maps, which were generated by the python package matplotlib (Hunter, 2007) and the chemoinformatics toolkit CDPkit (Seidel and Langer, 2017). Interactions were analyzed by generating a structure-based pharmacophore model at every saved frame of the MD trajectories and subsequently analyzing the frequency of the individual features. The interaction types were defined and described as pharmacophore features in the LigandScout 
user manual, including hydrophobic $(\mathrm{H})$, hydrogen bond (HB) acceptor/donor, positive ionizable (PI) and aromatic (AR) features. The ligands were decomposed into five areas (Figure 4A and Supplementary Figure S2): the pyridine (Ring A), the benzene (Ring B), the thiazolidinedione (Ring C), the linker connecting pyridine and benzene (Linker D), and the linker connecting benzene and thiazolidinedione (Linker E). The frequencies of interactions observed were numbered and colored in the interaction map.

\section{Electrophysiology}

Inside-out patch clamp electrophysiology was performed as described previously (Harakalova et al., 2012). In short, HEK293T cells were cultured on $10 \mathrm{~mm}$ glass coverslips and transfected with $0.16 \mu \mathrm{g}$ of rat pCMV6-Kir6.2, $0.16 \mu \mathrm{g}$ of rat pCMV6-SUR2A and $0.08 \mu \mathrm{g}$ of pEGFP1 expression constructs. Measurements were performed using an AxoPatch 200B amplifier controlled by pClamp 9 software (Molecular Devices) at $22^{\circ} \mathrm{C}$ using a ramp protocol ranging from -100 to $+100 \mathrm{mV}$ in $5 \mathrm{~s}$ from a holding potential of $-40 \mathrm{mV}$. The sampling rate was $50 \mathrm{kHz}$, filter frequency was $2 \mathrm{kHz}$. Bath solution contained $131 \mathrm{mM} \mathrm{KCl}, 1 \mathrm{mM}$ EGTA, $7.2 \mathrm{mM}$ $\mathrm{K}_{2} \mathrm{HPO}_{4}, 2.8 \mathrm{mM} \mathrm{KH} \mathrm{PO}_{4}, 1 \mathrm{mM} \mathrm{MgCl}$, and $\mathrm{pH} 7.20 / \mathrm{KOH}$. The pipette solution contained $145 \mathrm{mM} \mathrm{KCl}, 1 \mathrm{mM} \mathrm{CaCl}_{2}, 1 \mathrm{mM}$ $\mathrm{MgCl}_{2}, 5 \mathrm{mM}$ HEPES, and $\mathrm{pH} 7.40 / \mathrm{KOH}$. Pipette resistance was 1.5-3 M $\Omega$. Data were not corrected for rundown, which was less than $10 \%$ at $10 \mathrm{~min}$ as shown earlier (Houtman et al., 2019). All measurements were performed within a timeframe of 8-10 $\mathrm{min}$. Fractional block at -80 and $+50 \mathrm{mV}$ was determined by dividing current levels obtained with test compound containing solutions by current levels of control traces recorded in the absence of test compound. Statistics (unpaired Students $t$-tests (two tailed)) were performed using Kaleidagraph 4.0 software (Synergy Software, Reading, PA, United States).

Betaxolol (Sigma-Aldrich, St. Louis MO, United States) and Ritodrine (Sigma-Aldrich) were dissolved in $\mathrm{H}_{2} \mathrm{O}$ at

\section{REFERENCES}

Abraham, M. J., Murtola, T., Schulz, R., Páll, S., Smith, J. C., Hess, B., et al. (2015). Gromacs: high performance molecular simulations through multi-level parallelism from laptops to supercomputers. SoftwareX 1-2, 19-25. doi: 10. 1016/j.softx.2015.06.001

Agency European Medicines (2010). European Medicines Agency: EMA/585784/2010 - European Medicines Agency Recommends Suspension of Avandia, Avandamet and Avaglim. Available at: http://www.ema.europa. eu/docs/en_GB/document_library/Press_release/2010/09/WC500096996.pdf (accessed May 16, 2018).

Ashcroft, F. M. (2005). ATP-sensitive potassium channelopathies: focus on insulin secretion. J. Clin. Invest. 115, 2047-2058. doi: 10.1172/JCI25495

Babiker, T., Vedovato, N., Patel, K., Thomas, N., Finn, R., Männikkö, R., et al. (2016). Successful transfer to sulfonylureas in KCNJ11 neonatal diabetes is determined by the mutation and duration of diabetes. Diabetologia 59, 1162-1166. doi: 10.1007/s00125-016-3921-8

Berendsen, H. J. C., Grigera, J. R., and Straatsma, T. P. (1987). The missing term in effective pair potentials. J. Phys. Chem. 91, 6269-6271. doi: 10.1021/ j100308a038

Berger, O., Edholm, O., and Jähnig, F. (1997). Molecular dynamics simulations of a fluid bilayer of dipalmitoylphosphatidylcholine at full hydration, constant
$100 \mathrm{mM}$. Travoprost (MedChemExpress, Monmouth Junction, NJ, United States) was dissolved in DMSO at $10 \mathrm{mM}$. Test compounds were diluted in bath solution at the indicated concentrations before the start of measurements.

\section{AUTHOR CONTRIBUTIONS}

$\mathrm{XC}, \mathrm{MW}, \mathrm{AG}$, and $\mathrm{MH}$ performed the research. AS-W and $\mathrm{MvdH}$ designed the study. XC, MW, E-MZ-P, AG, MH, TL, MvdH, and AS-W analyzed the data. AS-W, MW, MvdH, and XC wrote the manuscript. All authors reviewed the manuscript.

\section{FUNDING}

This work was supported by the Austrian Science Fund (FWF; http://www.fwf.ac.at). AS-W and XC are supported by FWF grant I2101 (E-RARE 2). AS-W, XC, and E-MZ-P are supported by the doctoral program "Molecular drug targets" W1232 (FWF). $\mathrm{XC}$ is supported by the dissertation completion fellowship from the University of Vienna. $\mathrm{MvdH}$ and $\mathrm{MH}$ are supported by the E-Rare 2 Joint Transnational CantuTreat program.

\section{ACKNOWLEDGMENTS}

The computational results presented have been achieved in part using the Vienna Scientific Cluster (VSC). This manuscript has been released as a Pre-Print at BioRxiv (Chen et al., 2019).

\section{SUPPLEMENTARY MATERIAL}

The Supplementary Material for this article can be found online at: https://www.frontiersin.org/articles/10.3389/fphar. 2019.00549/full\#supplementary-material

pressure, and constant temperature. Biophys. J. 72, 2002-2013. doi: 10.1016/ S0006-3495(97)78845-3

Borschel, W. F., Wang, S., Lee, S., and Nichols, C. G. (2017). Control of kir channel gating by cytoplasmic domain interface interactions. J. Gen. Physiol. 149, 561-576. doi: 10.1085/jgp.201611719

Brown, J. D., and Plutzky, J. (2007). Peroxisome proliferator-activated receptors as transcriptional nodal points and therapeutic targets. Circulation 115, 518-533. doi: 10.1161/CIRCULATIONAHA.104.475673

Brownstein, C. A., Towne, M. C., Luquette, L. J., Harris, D. J., Marinakis, N. S., Meinecke, P., et al. (2013). Mutation of KCNJ8 in a patient with Cantú syndrome with unique vascular abnormalities - support for the role of K(ATP) channels in this condition. Eur. J. Med. Genet. 56, 678-682. doi: 10.1016/j.ejmg. 2013.09.009

Bussi, G., Donadio, D., and Parrinello, M. (2007). Canonical sampling through velocity rescaling. J. Chem. Phys. 126:014101. doi: 10.1063/1.240 8420

Cantú, J. M., Garcia-Cruz, D., Sánchez-Corona, J., Hernández, A., and Nazará, Z. (1982). A distinct osteochondrodysplasia with hypertrichosis-Individualization of a probable autosomal recessive entity. Hum. Genet. 60, 36-41. doi: 10.1007/ BF00281261

Chen, I. S., Tateyama, M., Fukata, Y., Uesugi, M., and Kubo, Y. (2017). Ivermectin activates GIRK channels in a PIP2-dependent, G $\beta \gamma$-independent manner and 
an amino acid residue at the slide helix governs the activation. J. Physiol. 595, 5895-5912. doi: 10.1113/JP274871

Chen, X., Garon, A., Wieder, M., Houtman, M. J. C., Zangerl-Plessl, E. M., Langer, T., et al. (2019). Computational identification of novel Kir6 channel inhibitors. BioRxiv [preprint]. Available at: https://doi.org/10.1101/539460 (accessed May 10, 2019).

Cooper, P. E., McClenaghan, C., Chen, X., Stary-Weinzinger, A., and Nichols, C. G. (2017). Conserved functional consequences of disease-associated mutations in the slide helix of Kir6.1 and Kir6.2 subunits of the ATP-sensitive potassium channel. J. Biol. Chem. 292, 17387-17398. doi: 10.1074/jbc.M117. 804971

Cooper, P. E., Reutter, H., Woelfle, J., Engels, H., Grange, D. K., van Haaften, G., et al. (2014). Cantú syndrome resulting from activating mutation in the KCNJ8 gene. Hum. Mutat. 35, 809-813. doi: 10.1002/humu.22555

Cox, P. J., Ryan, D. A., Hollis, F. J., Harris, A. M., Miller, A. K., Vousden, M., et al. (2000). Absorption, disposition, and metabolism of rosiglitazone, a potent thiazolidinedione insulin sensitizer, in humans. Drug Metab. Dispos. 28, $772-780$.

Crawford, R. M., Budas, G. R., Jovanović, S., Ranki, H. J., Wilson, T. J., Davies, A. M., et al. (2002). M-LDH serves as a sarcolemmal KATP channel subunit essential for cell protection against ischemia. EMBO J. 21, 3936-3948. doi: $10.1093 /$ emboj/cdf388

Darden, T., York, D., and Pedersen, L. (1993). Particle mesh ewald: an N.log(N) method for ewald sums in large systems. J. Chem. Phys. 98, 10089-10092. doi: $10.1063 / 1.464397$

Dart, C., and Standen, N. B. (1995). Activation of ATP-dependent K+ channels by hypoxia in smooth muscle cells isolated from the pig coronary artery. J. Physiol. 483, 29-39. doi: 10.1113/jphysiol.1995.sp020565

De Boer, T., Nalos, L., Stary, A., Kok, B., Houtman, M., Antoons, G., et al. (2010). The anti-protozoal drug pentamidine blocks KIR2.X-mediated inward rectifier current by entering the cytoplasmic pore region of the channel. Br. J. Pharmacol. 159, 1532-1541. doi: 10.1111/j.1476-5381.2010.00658.x

Della Manna, T., Battistim, C., Radonsky, V., Savoldelli, R. D., Damiani, D., Kok, F., et al. (2008). Glibenclamide unresponsiveness in a Brazilian child with permanent neonatal diabetes mellitus and DEND syndrome due to a C166Y mutation in KCNJ11 (Kir6.2) gene. Arq. Bras. Endocrinol. Metab. 52, 1350-1355. doi: 10.1590/S0004-27302008000800024

Efron, B. (1979). Bootstrap methods: another look at the Jackknife. Ann. Stat. 7, 1-26. doi: 10.1214/aos/1176344552

Ferrer, T., Ponce-Balbuena, D., López-Izquierdo, A., Aréchiga-Figueroa, I. A., De Boer, T. P., Van Der Heyden, M. A. G., et al. (2011). Carvedilol inhibits Kir2.3 channels by interference with PIP2-channel interaction. Eur. J. Pharmacol. 668, 72-77. doi: 10.1016/j.ejphar.2011.05.067

Frisch, M. J., Trucks, G. W., Schlegel, H. B., Scuseria, G. E., Robb, M. A., Cheeseman, J. R., et al. (2013). Gaussian 09, Revision D.01. Wallingford CT: Gaussian. Inc.

Gribble, F. M., and Reimann, F. (2003). Sulphonylurea action revisited: the postcloning era. Diabetologia 46, 875-891. doi: 10.1007/s00125-003-1143-3

Guex, N., and Peitsch, M. C. (1997). SWISS-MODEL and the swiss-Pdb viewer: an environment for comparative protein modeling. Electrophoresis 18, 2714-2723. doi: 10.1002/elps.1150181505

Hancox, J. C. (2011). Cardiac ion channel modulation by the hypoglycaemic agent rosiglitazone. Br. J. Pharmacol. 163, 496-498. doi: 10.1111/j.1476-5381.2011. 01281.x

Harakalova, M., Van Harssel, J. J. T., Terhal, P. A., Van Lieshout, S., Duran, K., Renkens, I., et al. (2012). Dominant missense mutations in ABCC9 cause Cantú syndrome. Nat. Genet. 44, 793-796. doi: 10.1038/ng.2324

Hess, B., Bekker, H., Berendsen, H. J. C., and Fraaije, J. G. E. M. (1997). LINCS: a linear constraint solver for molecular simulations. J. Comput. Chem. 18, 1463-1472.

Heyden, M., Stary-Weinzinger, A., and Sanchez-Chapula, J. (2013). Inhibition of cardiac inward rectifier currents by cationic amphiphilic drugs. Curr. Mol. Med. 13, 1284-1298. doi: 10.2174/1566524011313999 0043

Hornak, V., Abel, R., Okur, A., Strockbine, B., Roitberg, A., and Simmerling, C. (2006). Comparison of multiple amber force fields and development of improved protein backbone parameters. Proteins 65, 712-725. doi: 10.1002/ prot. 21123
Houtman, M. J. C., Chen, X., Qile, M., Duran, K., Van Haaften, G., StaryWeinzinger, A., et al. (2019). Glibenclamide and HMR1098 normalize Cantú syndrome-associated gain-of-function currents. J. Cell. Mol. Med. (in press). doi: $10.1111 /$ jcmm.14329

Huang, C. L., Feng, S. Y., and Hilgemann, D. W. (1998). Direct activation of inward rectifier potassium channels by PIP2 and its stabilization by G beta gamma. Nature 391, 803-806. doi: 10.1038/35882

Hub, J. S., De Groot, B. L., and Van Der Spoel, D. (2010). g_whams-a free weighted histogram analysis implementation including robust error and autocorrelation estimates. J. Chem. Theory Comput. 6, 3713-3720. doi: 10.1021/ct100 $494 \mathrm{z}$

Hunter, J. D. (2007). Matplotlib: a 2D graphics environment. Comput. Sci. Eng. 9, 99-104. doi: 10.1109/MCSE.2007.55

Jeong, I., Choi, B., and Hahn, S. (2011). Rosiglitazone inhibits Kv4.3 potassium channels by open-channel block and acceleration of closed-state inactivation. Br. J. Pharmacol. 163, 510-520. doi: 10.1111/j.1476-5381.2011.01210.x

Jones, G., Willett, P., Glen, R. C., Leach, A. R., and Taylor, R. (1997). Development and validation of a genetic algorithm for flexible docking. J. Mol. Biol. 267, 727-748. doi: 10.1006/jmbi.1996.0897

Kharade, S. V., Nichols, C., and Denton, J. S. (2016). The shifting landscape of KATP channelopathies and the need for "sharper" therapeutics. Future Med. Chem. 8, 789-802. doi: 10.4155/fmc-2016-0005

Kikuta, J. I., Ishii, M., Kishimoto, K., and Kurachi, Y. (2006). Carvedilol blocks cardiac KATP and KG but not IK1 channels by acting at the bundle-crossing regions. Eur. J. Pharmacol. 529, 47-54. doi: 10.1016/j.ejphar.2005.10.059

Kuhn, M., Campillos, M., Letunic, I., Jensen, L. J., and Bork, P. (2010). A side effect resource to capture phenotypic effects of drugs. Mol. Syst. Biol. 6:343. doi: $10.1038 / \mathrm{msb} .2009 .98$

Kuhn, M., Letunic, I., Jensen, L. J., and Bork, P. (2016). The SIDER database of drugs and side effects. Nucleic Acids Res. 44, D1075-D1079. doi: 10.1093/nar/ gkv1075

Kusalik, P. G., and Svishchev, I. M. (1994). The spatial structure in liquid water. Science 265, 1219-1221. doi: 10.1126/science.265.5176.1219

Law, V., Knox, C., Djoumbou, Y., Jewison, T., Guo, A. C., Liu, Y., et al. (2014). DrugBank 4.0: shedding new light on drug metabolism. Nucleic Acids Res. 42, D1091-D1097. doi: 10.1093/nar/gkt1068

Lee, K. P. K., Chen, J., and MacKinnon, R. (2017). Molecular structure of human KATP in complex with ATP and ADP. eLife 6:e32481. doi: 10.7554/eLife.32481

Lee, S.-J., Ren, F., Zangerl-Plessl, E.-M., Heyman, S., Stary-Weinzinger, A., Yuan, P., et al. (2016). Structural basis of control of inward rectifier Kir2 channel gating by bulk anionic phospholipids. J. Gen. Physiol. 148, 227-237. doi: 10. 1085/jgp.201611616

Li, N., Wu, J. X., Ding, D., Cheng, J., Gao, N., and Chen, L. (2017). Structure of a pancreatic ATP-sensitive potassium channel. Cell 168, 101-110.e10. doi: 10.1016/j.cell.2016.12.028

LigandScout User Manual (2010). Available at: http://www.inteligand.com/ ligandscout3/downloads/ligandscout-manual-2010-04-15.pdf (accessed May $16,2018)$.

Lin, Y.-W., Jia, T., Weinsoft, A. M., and Shyng, S.-L. (2003). Stabilization of the activity of ATP-sensitive potassium channels by ion pairs formed between adjacent Kir6.2 subunits. J. Gen. Physiol. 122, 225-237. doi: 10.1085/jgp. 200308822

Lu, L., Reiter, M. J., Xu, Y., Chicco, A., Greyson, C. R., and Schwartz, G. G. (2008). Thiazolidinedione drugs block cardiac KATP channels and may increase propensity for ischaemic ventricular fibrillation in pigs. Diabetologia 51, 675-685. doi: 10.1007/s00125-008-0924-0

MacGregor, G. G., Dong, K., Vanoye, C. G., Tang, L., Giebisch, G., and Hebert, S. C. (2002). Nucleotides and phospholipids compete for binding to the C terminus of KATP channels. Proc. Natl. Acad. Sci. U.S.A. 99, 2726-2731. doi: 10.1073/pnas.042688899

Martin, G. M., Kandasamy, B., DiMaio, F., Yoshioka, C., and Shyng, S.-L. (2017a). Anti-diabetic drug binding site in a mammalian KATP channel revealed by Cryo-EM. eLife 6:e31054. doi: 10.7554/eLife.31054

Martin, G. M., Yoshioka, C., Rex, E. A., Fay, J. F., Xie, Q., Whorton, M. R., et al. (2017b). Cryo-EM structure of the ATP-sensitive potassium channel illuminates mechanisms of assembly and gating. eLife 6:e24149. doi: 10.7554/eLife.24149

Martí-Renom, M. A., Stuart, A. C., Fiser, A., Sánchez, R., Melo, F., and Šali, A. (2000). Comparative protein structure modeling of genes and genomes. Annu. 
Rev. Biophys. Biomol. Struct. 29, 291-325. doi: 10.1146/annurev.biophys.29. 1.291

Matsuo, M., Kioka, N., Amachi, T., and Ueda, K. (1999). ATP binding properties of the nucleotide-binding folds of SUR1. J. Biol. Chem. 274, 37479-37482. doi: $10.1074 /$ jbc. 274.52 .37479

Matsuo, M., Tanabe, K., Kioka, N., Amachi, T., and Ueda, K. (2000). Different binding properties and affinities for ATP and ADP among sulfonylurea receptor subtypes, SUR1, SUR2A, and SUR2B. J. Biol. Chem. 275, 28757-28763. doi: 10.1074/jbc.M004818200

Nelson, P. T., Wang, W. X., Wilfred, B. R., Wei, A., Dimayuga, J., Huang, Q., et al. (2015). Novel human ABCC9/SUR2 brain-expressed transcripts and an eQTL relevant to hippocampal sclerosis of aging. J. Neurochem. 134, 1026-1039. doi: $10.1111 /$ jnc. 13202

Nichols, C. G., and Lederer, W. J. (1991). Adenosine triphosphate-sensitive potassium channels in the cardiovascular system. Am. J. Physiol. Hear. Circ. Physiol. 261, 1675-1686. doi: 10.1152/ajpheart.1991.261.6.H1675

Nichols, C. G., Singh, G. K., and Grange, D. K. (2013). KATP channels and cardiovascular disease: suddenly a syndrome. Circ. Res. 112, 1059-1072. doi: 10.1161/CIRCRESAHA.112.300514

Parrinello, M., and Rahman, A. (1981). Polymorphic transitions in single crystals: a new molecular dynamics method. J. Appl. Phys. 52, 7182-7190. doi: 10.1063/ 1.328693

Pearson, E. R., Flechtner, I., Njølstad, P. R., Malecki, M. T., Flanagan, S. E., Larkin, B., et al. (2006). Switching from insulin to oral sulfonylureas in patients with diabetes due to Kir6.2 mutations. N. Engl. J. Med. 355, 467-477. doi: 10.1056/ NEJMoa061759

Piao, H., Cui, N., Xu, H., Mao, J., Rojas, A., Wang, R., et al. (2001). Requirement of multiple protein domains and residues for gating K(ATP) channels by intracellular pH. J. Biol. Chem. 276, 36673-36680. doi: 10.1074/jbc. M106123200

Remedi, M. S., Friedman, J. B., and Nichols, C. G. (2017). Diabetes induced by gain-of-function mutations in the Kir6.1 subunit of the KATP channel. J. Gen. Physiol. 149, 75-84. doi: 10.1085/jgp.201611653

Remedi, M. S., and Nichols, C. G. (2009). Hyperinsulinism and diabetes: genetic dissection of $\beta$ cell metabolism-excitation coupling in mice. Cell Metab. 10, 442-453. doi: 10.1016/j.cmet.2009.10.011

Scherer, D., Schworm, B., Seyler, C., Xynogalos, P., Scholz, E. P., Thomas, D., et al. (2017). Inhibition of inwardly rectifying Kir2.x channels by the novel anticancer agent gambogic acid depends on both pore block and PIP2 interference. Naunyn. Schmiedebergs. Arch. Pharmacol. 390, 701-710. doi: 10.1007/s00210017-1372-5

Scurr, I., Wilson, L., Lees, M., Robertson, S., Kirk, E., Turner, A., et al. (2011). Cantú syndrome: report of nine new cases and expansion of the clinical phenotype. Am. J. Med. Genet. Part A 155, 508-518. doi: 10.1002/ajmg.a.33885

Seidel, T., and Langer, T. (2017). CDPkit, the Chemical Data Processing Toolkit. Available at: https://github.com/aglanger/CDPKit (accessed May 16, 2018).

Shyng, S. L., and Nichols, C. G. (1998). Membrane phospholipid control of nucleotide sensitivity of K(ATP) channels. Science 282, 1138-1141. doi: 10.1126/ science. 282.5391 .1138

Szentandrássy, N., Harmati, G., Bárándi, L., Simkõ, J., Horváth, B., Magyar, J., et al. (2011). Effects of rosiglitazone on the configuration of action potentials and ion currents in canine ventricular cells. Br. J. Pharmacol. 163, 499-509. doi: 10.1111/j.1476-5381.2011.01215.x

Takanari, H., Nalos, L., Stary-Weinzinger, A., De Git, K. C. G., Varkevisser, R., Linder, T., et al. (2013). Efficient and specific cardiac IK1 inhibition by a new pentamidine analogue. Cardiovasc. Res. 99, 203-214. doi: 10.1093/cvr/ cvt103

Tanabe, K., Tucker, S. J., Matsuo, M., Proks, P., Ashcroft, F. M., Seino, S., et al. (1999). Direct photoaffinity labeling of the Kir6.2 subunit of the ATP-sensitive K+ channel by 8-azido-ATP. J. Biol. Chem. 274, 3931-3933. doi: 10.1074/jbc. 274.7.3931

Trapp, S., Proks, P., Tucker, S. J., and Ashcroft, F. M. (1998). Molecular analysis of ATP-sensitive $\mathrm{K}$ channel gating and implications for channel inhibition by ATP. J. Gen. Physiol. 112:333. doi: 10.1085/jgp.112.3.333
U.S. Food and Drug Administration (2011). Reminder to Healthcare Providers and Patients to Enroll in the Avandia-Rosiglitazone Medicines Access Program. FDA Drug Saf. Commun. Available at: https://www.fda.gov/Drugs/DrugSafety/ ucm277629.htm (accessed May 16, 2018).

Ueda, K., Komine, J., Matsuo, M., Seino, S., and Amachi, T. (1999). Cooperative binding of ATP and MgADP in the sulfonylurea receptor is modulated by Figure. Proc. Natl. Acad. Sci. U.S.A. 96, 1268-1272. doi: 10.1073/pnas.96.4.1268

Van Bon, B. W. M., Gilissen, C., Grange, D. K., Hennekam, R. C. M., Kayserili, H., Engels, H., et al. (2012). Cantú syndrome is caused by mutations in ABCC9. Am. J. Hum. Genet. 90, 1094-1101. doi: 10.1016/j.ajhg.2012.04.014

Vanoye, C. G., MacGregor, G. G., Dong, K., Tang, L., Buschmann, A. S., Hall, A. E., et al. (2002). The carboxyl termini of KATP channels bind nucleotides. J. Biol. Chem. 277, 23260-23270. doi: 10.1074/jbc.M112004200

Verlet, L. (1967). Computer "experiments" on classical fluids. I. Thermodynamical properties of lennard-jones molecules. Phys. Rev. 159, 98-103. doi: 10.1103/ PhysRev.159.98

Wang, J., Wang, W., Kollman, P. A., and Case, D. A. (2006). Automatic atom type and bond type perception in molecular mechanical calculations. J. Mol. Graph. Model. 25, 247-260. doi: 10.1016/j.jmgm.2005.12.005

Wang, J., Wolf, R. M., Caldwell, J. W., Kollman, P. A., and Case, D. A. (2004). Development and testing of a general Amber force field. J. Comput. Chem. 25, 1157-1174. doi: 10.1002/jcc.20035

Whorton, M. R., and MacKinnon, R. (2011). Crystal structure of the mammalian GIRK2 $\mathrm{K}+$ channel and gating regulation by $\mathrm{G}$ proteins, PIP2, and sodium. Cell 147, 199-208. doi: 10.1016/j.cell.2011.07.046

Wieder, M., Garon, A., Perricone, U., Boresch, S., Seidel, T., Almerico, A. M., et al. (2017). Common hits approach: combining pharmacophore modeling and molecular dynamics simulations. J. Chem. Inf. Model. 57, 365-385. doi: 10.1021/acs.jcim.6b00674

Wolber, G., and Langer, T. (2005). LigandScout: 3-D pharmacophores derived from protein-bound ligands and their use as virtual screening filters. J. Chem. Inf. Model. 45, 160-169. doi: 10.1021/ci049885e

Wu, J. X., Ding, D., Wang, M., Kang, Y., Zeng, X., and Chen, L. (2018). Ligand binding and conformational changes of SUR1 subunit in pancreatic ATPsensitive potassium channels. Protein Cell 9, 553-567. doi: 10.1007/s13238-0180530-y

Yu, L., Jin, X., Cui, N., Wu, Y., Shi, Z., Zhu, D., et al. (2012). Rosiglitazone selectively inhibits KATP channels by acting on the KIR6 subunit. $\mathrm{Br}$. J. Pharmacol. 167, 26-36. doi: 10.1111/j.1476-5381.2012.01934.x

Yu, L., Jin, X., Yang, Y., Cui, N., and Jiang, C. (2011). Rosiglitazone inhibits vascular KATP channels and coronary vasodilation produced by isoprenaline. Br. J. Pharmacol. 164, 2064-2072. doi: 10.1111/j.1476-5381.2011.01539.x

Zhang, H., He, C., Yan, X., Mirshahi, T., and Logothetis, D. E. (1999). Activation of inwardly rectifying $\mathrm{K}+$ channels by distinct PtdIns $(4,5) \mathrm{P} 2$ interactions. Nat. Cell Biol. 1, 183-188. doi: 10.1038/11103

Zhang, R. S., Wright, J. D., Pless, S. A., Nunez, J. J., Kim, R. Y., Li, J. B. W., et al. (2015). A conserved residue cluster that governs kinetics of ATP-dependent gating of Kir6.2 potassium channels. J. Biol. Chem. 290, 15450-15461. doi: 10.1074/jbc.M114.631960

Zingman, L. V., Alekseev, A. E., Hodgson-Zingman, D. M., and Terzic, A. (2007). ATP-sensitive potassium channels: metabolic sensing and cardioprotection. J. Appl. Physiol. 103, 1888-1893. doi: 10.1152/japplphysiol.00747.2007

Conflict of Interest Statement: The authors declare that the research was conducted in the absence of any commercial or financial relationships that could be construed as a potential conflict of interest.

Copyright (C) 2019 Chen, Garon, Wieder, Houtman, Zangerl-Plessl, Langer, van der Heyden and Stary-Weinzinger. This is an open-access article distributed under the terms of the Creative Commons Attribution License (CC BY). The use, distribution or reproduction in other forums is permitted, provided the original author(s) and the copyright owner(s) are credited and that the original publication in this journal is cited, in accordance with accepted academic practice. No use, distribution or reproduction is permitted which does not comply with these terms. 